\title{
Editorial
}

\section{State of the journal}

The fournal of Accident $\mathcal{E}$ Emergency Medicine continues to evolve and flourish thanks to the excellent contributions of authors, the Editorial Board, and the team at the BMJ Publishing Group. The journal has developed a maturity which will ensure its position among the leading international emergency medicine literature.

In 1998, the journal received 336 manuscripts for consideration for publication, an increase of $15 \%$ over 1997. The overall rejection rate for papers was $34 \%$. The mean time from receipt of a paper to a decision with regard to publication was 62 days in 1998, compared with 73 days in 1997.

During 1998 there were several initiatives which proved to be highly successful and popular with the readership, including the series "Clinical management" coordinated by Jim Wardrope and the publication of evidence based material in the "Best BETs" series coordinated by Kevin Mackway-Jones. For 1999, series are in preparation covering research and statistics in emergency medicine, the emergency medicine/intensive care interface, alcohol related issues, ethics, interpretation of electrocardiographs, and hand injuries. In addition, it is hoped to develop the potential of the journal to be a formal component of continuing professional development, initially with readers sending in answers to questions set at the end of the papers on clinical management. If this proves successful, then more ambitious interactive opportunities will follow.

The journal will continue to encourage and publish original research of an increasingly high scientific standard and the balance will be maintained between the publication of research and review material. Submissions of case reports and emergency casebook topics are welcomed. The journal intends to move away from publishing those case reports dealing with conditions which may be encountered only once in a career. However, when the case report illustrates an important clinical principle and is supported by a comprehensive review of the recent relevant literature, then publication is more likely to be supported.

During 1998, the BMJ Publishing Group arranged a readership survey and the high response rate was greatly appreciated. There was considerable favourable comment with regard to the current state of play and direction of the journal. Many constructively critical comments were received, including concerns that the scientific quality of research papers should improve and that further articles dealing with management issues should be published, among others. All the comments have been noted and will be discussed in detail at the next Editorial Board meeting.

One of the many advantages of being part of the BMJ Publishing Group is the opportunity to be involved in new publishing initiatives including developments in electronic publishing and peer review. Recently, there has been concern with regard to authorship, particularly the concept of gift authorship where authors are cited for a role which may have been nominal at best. The journal will follow the $B M F$ lead and require that the individual contributions of authors named on the paper be specified. Further details of this will be sent to authors when finally revising their paper.

Your comments and suggestions for the future content and direction of the journal are always welcome. The squad of reviewers for papers submitted to the journal continues to grow and applications from new members are invited, particularly newly appointed consultants and registrars in the final year of training in the UK and internationally, especially Europe and the Far East. Please contact the Editor at the journal if you are interested.

Finally, it is a great pleasure to acknowledge and express my thanks to the Associate Editors, Peter Driscoll and Jim Wardrope, and the editorial team at the BMJ Publishing Group for their unfailing enthusiasm and support.

JOHN HEYWORTH Editor

$\begin{array}{ccc}\begin{array}{c}\text { Emergency } \\ \text { casebooks }\end{array} & 155 & \text { Glioblastoma presenting as carbon monoxide poisoning } M \text { Turner, } R \mathcal{F} \text { Clark } \\ & 156 & \text { Covert tamponade } M \text { G fenkins, D Cochrane } \\ & 157 & \text { Acute airway obstruction-an unusual cause } D \text { Williamson, } T \text { Llewellyn }\end{array}$

Letters to the editor 158 Non-invasive cardiac output assessment in children C Childs, P Dark

159 Safe use of thrombolysis in acute myocardial infarction $\mathcal{F}$ Edhouse

159 Capnography and "major" accident and emergency departments in East Anglia $R$ Florance, $R$ Griffiths, $A$ Cope

159 Violence in the accident and emergency department: liaison with the police $\mathcal{F}$ Bache, $D$ Chambers, $P$ Guildford 